\title{
Produção narrativa oral de crianças e o texto literário
}

\section{Children's oral narrative production and literary text}

https://doi.org/10.34112/2317-0972a2019v37n76p109-124

Karin Cozer de Campos ${ }^{1}$

RESUMO: O trabalho trata da relação entre a produção narrativa oral de crianças e o texto literário. $\mathrm{O}$ objetivo é discutir como o texto literário pode contribuir para potencializar a produção narrativa oral das crianças no ambiente escolar. Toma-se como referência uma pesquisa desenvolvida com um grupo de crianças de uma escola pública. A principal estratégia metodológica foram oficinas de criação de histórias para estimular a produção narrativa oral das crianças. Algumas dessas oficinas tiveram como recurso obras da literatura infantil. Alguns resultados da pesquisa apontam que o texto literário potencializou a produção das narrativas orais das crianças, isto é, a possibilidade de fazer da narrativa literária uma narrativa pessoal. As crianças tomaram o texto literário como referência, reelaboraram-no e criaram as suas próprias histórias a partir de suas experiências, o que inspirou suas produções narrativas orais e seus processos criativos e imaginários.

Palavras-Chave: Produção narrativa oral de crianças; texto literário; narrativas pessoais.

ABSTRACT: This paper deals with the relationship between children's oral narrative production and literary text. The aim is to discuss how literary text can contribute to and optimize children's oral narrative production in the school environment. The reference used is a study conducted with a group of children attending a state school. Story creation

1. Universidade Estadual do Oeste do Paraná, Câmpus Francisco Beltrão, PR, Brasil. 
workshops were the main methodological strategy used to stimulate children's oral narrative production, with some workshops using Children's Literature as a tool. Some of the study's results indicate that literary text has potentiated the production of the children's oral narratives. The possibility of making personal narrative out of literary narrative. The children took the literary text as a reference, reworked it and created their own stories, containing their experiences, inspiring their oral narrative productions and their creative and imaginative processes.

KEYWORDS: Children's oral narrative production; literary text; personal narratives.

\section{CONSIDERAÇÕES INICIAIS}

O trabalho trata da relação entre produção narrativa oral de crianças e o texto literário. $\mathrm{O}$ objetivo é discutir como o texto literário pode contribuir para potencializar a produção narrativa oral das crianças no ambiente escolar. Toma-se como referência a pesquisa desenvolvida com um grupo de crianças com idade entre o9 e 10 anos, estudantes do $5^{\circ}$ ano dos anos iniciais do Ensino Fundamental de uma escola pública rural.

A investigação se insere em uma abordagem de pesquisa qualitativa e pode ser caracterizada como uma pesquisa narrativa (CLANDININ; CONNELLY, 2015), que se orientou pelos princípios do fazer pesquisa com crianças (PEREIRA, 2012; ABRAMOWICZ, 2011; DELGADO; MULLER, 2005; KRAMER, 2002).

A principal estratégia metodológica foram oficinas de criação de histórias para estimular a produção de narrativas orais a partir das experiências vividas pelas crianças. As oficinas foram organizadas para estimulá-las a narrarem suas experiências e, a partir disso, algumas estratégias foram criadas no desenvolvimento desse trabalho, como foi o caso das oficinas que tiveram como recurso obras da Literatura Infantil, de modo que o texto literário motivou as crianças a produzirem histórias que envolveram lembranças importantes para elas.

A partir disso, apresento, inicialmente, alguns procedimentos metodológicos das oficinas de criação de histórias que tiveram como recurso obras da literatura infantil e alguns exemplos de narrativas orais das crianças que foram produzidas a partir do encontro delas com o texto literário. Por fim, destaco alguns dos principais resultados e considerações da pesquisa relacionadas à discussão proposta neste artigo. 
OFICINAS DE CRIAÇÃO DE HISTÓRIAS COM OBRAS DA LITERATURA INFANTIL

Como uma estratégia metodológica da pesquisa, foram desenvolvidas oficinas de criação de histórias com as crianças. Essa iniciativa surgiu da relação com a pesquisa realizada por Girardello (2011a) ${ }^{2}$, que tinha como objetivo identificar e conhecer propostas de trabalho pedagógico que fossem potencialmente relevantes para os anos iniciais do Ensino Fundamental e que promovessem autoria e participação das crianças na produção de narrativas em diferentes linguagens (orais, escritas, visuais e/ou audiovisuais). Trata-se, especialmente, da experiência do Projeto Secret Histories da Ping Chong Company ${ }^{3}$, realizado em escolas públicas da cidade de Nova York. Um dos trabalhos desenvolvidos pela companhia, e que se tornou uma inspiração para as atividades de pesquisa de campo da investigação que realizei, são as "oficinas de criação de histórias de vida com crianças", que incluem narrações orais coletivas, em que as próprias crianças narram histórias que criaram coletivamente, a partir de experiências vividas.

Dentre as oficinas que desenvolvi na pesquisa, apresento neste texto algumas reflexões referentes às que tiveram obras da literatura infantil como estratégia metodológica para a produção narrativa oral das crianças, as quais foram assim intituladas: a) "Algo que vale ouro; algo que faz rir; algo que faz chorar", que teve como referência a obra Guilherme Augusto Araújo Fernandes (FOX, 1995); b) "A história de uma colcha de retalhos", c) "Nossas roupas contam histórias" e d) "Colcha de retalhos”, que tiveram como referência a obra literária Colcha de retalhos (SILVA, 2010).

A seguir, relato como cada uma dessas oficinas foi desenvolvida e apresento alguns exemplos de narrativas orais produzidas pelas crianças:

\section{A. "Algo que vale ouro; algo que faz rir; algo que faz chorar".}

Em um dos encontros, sugeri às crianças que pensassem em algo, qualquer coisa, que considerassem que as fizesse rir ou chorar ou, ainda, que para elas valesse

2. GIRARDELLO, G. "Cultura nos anos iniciais do ensino fundamental: produção narrativa infantil e imaginário midiático”. Relatório de Pesquisa do Estágio Pós-Doutoral 2010-2011. Urban Education Program - City University of New York/ Programa de Pós-Graduação em Educação - UFRGS/Fulbright/Capes.

3. Fundada há 35 anos pelo diretor de teatro e educador social nascido na Chinatown nova-iorquina Ping Chong, a companhia é uma referência muito importante no teatro norteamericano, cuja missão é explorar as intersecções entre raça, cultura, história, arte, mídia e tecnologia no mundo moderno (www.pingchong. org). (GIRARDELLO, 2011a, p. 12). 
ouro $^{4}$, e que a trouxessem para o encontro seguinte. Comentei que se tratava de um exercício "para irem para casa pensando" e que não era preciso, naquele momento, me darem a resposta. Inclusive, sugeri que elas tentassem guardar segredo sobre suas escolhas. Mas sabia que isso seria muito difícil para elas.

Reforcei junto às crianças que elas podiam trazer qualquer coisa, e que cada uma contaria uma história sobre o que trouxesse (seus significados). Para despertar a curiosidade das crianças, comentei que eu conhecia uma história sobre um menino que guardava coisas que para ele valiam ouro, que lhe faziam rir e que lhe faziam chorar, mas que essa história eu só contaria no próximo encontro.

Para orientar as crianças em suas narrações, indiquei que começassem suas histórias apresentando o que haviam trazido, depois contando o que para elas significava e a história relacionada e, principalmente, que tentassem pensar em vários detalhes para nos contar. Algumas histórias narradas pelas crianças:

Menina: - É, ele (apontando para seu urso) vale ouro para mim. Eu ganhei ele em fevereiro desse ano, e meu tio, quando ele veio pra cá, ele me trouxe um urso e pra minha irmã uma bonequinha. E daí ele me fez muito feliz. Quando eu fico alegre e chego em casa durmo com ele, e pra mim vale ouro.

Pesquisadora: - Por que entre tantas coisas que valem ouro para você, você escolheu o ursinho?

Menina: - Porque ele sempre tá comigo.

Menina: - É, aqui é minha família (apontando para uma foto), dá de todo mundo vê? É, eu trouxe essa foto porque ela vale ouro pra mim porque é minha família. Essa é minha mãe, sou eu quando eu tinha quatro anos, esse é meu pai e minha irmã, que agora tem dezesseis anos. Eu trouxe essa foto porque ela vale ouro pra mim, e foi no dia do aniversário da minha mãe, [foto] que faz cinco anos. É, eu dei essa foto pro meu pai porque mês passado era aniversário dele, e ela vale ouro pra mim porque é minha família e é muito importante pra mim.

4. Este exercício foi inspirado no relato da experiência de trabalho de uma professora do Colégio de Aplicação da UFSC, desenvolvido com crianças dos anos iniciais do Ensino Fundamental a partir da história Guilherme Augusto Araújo Fernandes (FOX, 1995). Este relato foi apresentado durante o Seminário Ler e compreender o texto literário: lições de estratégias de leitura, ministrado pela professora Renata Junqueira de Souza (abril de 2015). 
Menino: - Eu trouxe uma coisa que vale ouro, a minha amizade! É, na verdade eu ia trazer uma coisa que eu pensei em trazer ontem. Uma chupetinha que eu tenho desde quando eu nasci. Mas eu acabei me esquecendo, eu trouxe a minha amizade. Porque eu sempre tive ela e sempre vou trazer ela comigo pra onde eu for e ir.

Pesquisadora: - Que bonito!

Com relação às escolhas das crianças, algumas disseram que pensaram no que trazer um dia antes do encontro, algumas disseram que foi antes de sair de casa e outras que foi desde o primeiro dia, e que ao chegar em casa já sabiam o que gostariam de trazer. Mas foi possível observar semelhanças em alguns objetos trazidos por elas, como, por exemplo, fotografias. Penso que elas podem ter combinado ou trocado ideias juntas sobre o que trazer.

Como combinado, todos, inclusive eu, deveríamos trazer algo que nos fizesse rir, chorar, ou que para nós valesse ouro. Então, minha escolha foi algo que valia ouro. Para isso, eu levei uma "mala literária" com um livro e alguns objetos relacionados à história Guilherme Augusto Araújo Fernandes (FOX, 1995), que eu havia preparado para contar, e que tinha relação com o exercício proposto às crianças. A proposta de levar a "mala literária" foi baseada nas estratégias de leitura literária durante a "pré-leitura" -, que são apresentadas e discutidas por Souza (2010). Nas suas propostas, a autora usa a nomenclatura "cesta literária", mas, nesse caso, optei por "mala literária”, por se tratar de uma mala.

Iniciei apresentando às crianças uma "mala literária" que eu havia levado com alguns objetos relacionados à história. Abri a mala, apresentei os objetos, inclusive o livro da história, e perguntei-lhes o que imaginavam que para o menino da história aqueles objetos significavam (ovo, medalha, marionete, concha e bola). Algumas disseram que poderiam ser "lembranças, coisa antiga, coisas para ele se lembrar de quando ele era criança”. Para finalizar o encontro, narrei a história, isto é, realizei uma leitura com o livro, enquanto apresentava também os objetos da mala.

Durante a narração dessa história para as crianças, e considerando que foi a primeira vez que eu narrei uma para elas, pude observá-las muito atentas à história e à mala, que continha objetos que teriam seus significados revelados. Minha percepção foi de que aquele momento de audição de uma história de livro era muito prazeroso às crianças, e as suas expressões faciais e corporais evidenciaram isso, pois manifestavam atenção e envolvimento com a narrativa. Mas a manifestação delas de atenção e de escuta - porque havia um livro e objetos - não foi diferente 
das outras situações em que ouviram histórias narradas por elas e sobre elas apenas com a voz, o corpo e a memória.

\section{B. “A história de UMA COLCha de REtAlhos”.}

Apresentei às crianças o livro intitulado Colcha de retalhos (SILVA, 2010). A história é sobre uma vovó que reuniu várias histórias em uma colcha de retalhos e cada pedaço de tecido contava algo relacionado a lembranças e sentimentos de saudade. Iniciei apresentando a capa do livro às crianças para instigá-las a pensar em sobre o que poderia ser aquela história, e logo elas comentaram: "igual nosso tapete, roupa, retalho, tesoura, linha, uma colcha”.

Depois, perguntei às crianças sobre que história o escritor poderia ter criado a partir de uma colcha de retalhos, e elas disseram: "é que eles estavam com frio e por isso fizeram uma colcha; que ela (a vovó) achou ele (o menino) e deu uma coberta pra ele”. Em seguida narrei a história às crianças com o uso do livro.

Após isso, as crianças narraram histórias de que lembraram, e que tiveram como temas centrais, de maneira especial, a saudade e os avós:

Menina: - A minha é que a minha prima faleceu há um mês e pouco, e eu sinto muita saudade dela. Foi uma notícia muito chocante. A mãe do Andrei que trouxe a notícia lá em casa. A mãe dele chegou chorando, a minha mãe desesperada porque não sabia de nada.

Menino: - Ah, saudade do meu nono que morreu!

A saudade foi citada pelas crianças como mais uma palavra que elas encontraram para comunicar como se sentiam a partir de suas experiências e dar-lhes um sentido. Do mesmo modo, mais uma vez a narrativa literária potencializou as crianças a narrarem experiências pessoais, como é o caso da próxima oficina que apresento.

\section{C. “Nossas roupas contam histórias".}

A partir do encontro anterior (a história de uma Colcha de retalhos), pedi às crianças que trouxessem alguma roupa ou algum tecido que tivesse um significado muito importante para elas. Tal significado poderia não ser necessariamente 
relacionado às crianças, mas a qualquer pessoa que conhecessem. Pedi também que, ao trazerem a roupa ou o tecido, contassem uma história.

A maioria das crianças levou sua roupa de batizado. Há a possibilidade de que durante o intervalo dos encontros elas tenham trocado ideias sobre o que poderiam levar e uma pode ter influenciado a outra.

Destaco que em todos os encontros, antes de as crianças iniciarem suas narrações, eu buscava orientá-las a lembrarem de todos os detalhes possíveis de suas histórias, e indicava que utilizassem alguns elementos narrativos. Esse cuidado metodológico antes de as crianças narrarem oralmente é pautado pelo entendimento de que é importante haver um "procedimento de ensino do texto oral" às crianças, assim como há com os textos escritos, para que seja possível instituir legitimidade ao texto oral e desenvolver com as crianças suas potencialidades de produção (SCHNEUWLY; DOLZ, 2004, p. 151).

Igualmente, Macedo \& Sperb (2007, p. 236), ao discutirem o desenvolvimento da habilidade da criança para narrar experiências pessoais, destacam, a partir de autores $^{5}$ que também pesquisam narrativas infantis, que as perguntas servem como suporte para a narração e possibilitam às crianças ampliar suas respostas, porque as perguntas "fornecem uma codificação para as histórias, que as encorajam a fazerem conexões entre os eventos".

Destaco que, num momento mais avançado da pesquisa, como no dia dessa oficina, não precisei mais repetir os elementos narrativos; as crianças mesmas indicaram ao grupo o que deveria ser considerado no roteiro da narração: "Quem estava lá é uma coisa que tem que falar. Quando. Por que. Como se sentia...”

\section{A roupa do meu batizado}

Menino: - Eu trouxe minha roupa de batizado. É porque eu gosto muito dela e tava no meu batizado o meu padrinho, a minha madrinha, a minha mãe, meu pai, a minha prima e o padre. Foi no dia vinte e cinco de junho, quatro horas, num sábado, na matriz.

\section{O casaquinho de 52 anos}

Professora da turma: - Eu vou contar deste casaquinho aqui primeiro. Ele era do meu marido, é do meu marido, que o meu marido ainda está vivo e está com 52 anos e ele usou.

5. Sobre o uso de perguntas durante a narração infantil, Macedo \& Sperb tomam como referência as pesquisas de Low e Durkin (2001) "Individual diferences and consistency in maternal talk style during joint story encoding and retrospection: associations with children's long term recall”, e Peterson e McCabe (2003) "A social interacionist account of developing decontextualized narrative skill”. 
O dia que a minha sogra me deu para guardar eu disse: - Mas não serviu nele? Ela disse: - Usou um monte de vezes isso, só quando a gente ia na igreja. Porque era muito bonito na época. E daí, tinha uma touquinha, só que eu não achei a touquinha ontem. Fazia dias que eu queria procurar e eu fui deixando e deixando, não achei, eu trouxe só o casaquinho. Enquanto eu conseguir eu vou segurar para mim, de repente eu possa ter netos, não tenho ainda, de repente tenho um neto e posso mostrar alguma coisa. Quem fez foi uma sobrinha da minha sogra que é prima do meu marido, que fez na época e deu.

D. “Colcha de Retalhos”.

A experiência é compreendida como matéria-prima na relação com a narrativa. O conteúdo da experiência é alicerce para a tecitura das palavras que se juntam e constituem histórias, as quais são narradas e ouvidas, e depois novamente narradas. Um movimento que faz com que as histórias permaneçam sendo contadas e recontadas constantemente, cada qual ao modo do ouvinte e narrador.

No conjunto da obra benjaminiana, alguns temas, como o declínio da experiência e o fim da narração tradicional, acompanharam o pensamento do autor desde seus primeiros escritos e ainda são pertinentes para se pensar sobre a experiência do sujeito na contemporaneidade. A constatação de Benjamin é de que a experiência representa aquilo que pode ser transmitido pela palavra (BENJAMIN, 1994), mas que para o autor teria se perdido (GAGNEBIN, 2011).

Para Benjamin (1994, p. 204-205), o tédio é compreendido como "o pássaro de sonho que choca os ovos da experiência”. No entanto, para o autor, isso não existe mais. E, por isso, "desaparece o dom de ouvir, e desaparece a comunidade dos ouvintes", pois "contar histórias sempre foi a arte de contá-las de novo, e ela se perde quando as histórias não são mais conservadas. Ela se perde porque ninguém mais fia ou tece enquanto ouve a história”. Assim, Benjamin enfatiza que não há mais a troca de experiências, as quais se relacionam com a tradição e podem ser compartilhadas e retomadas pela palavra.

Foi a partir desses preceitos benjaminianos que a oficina "Colcha de retalhos" foi pensada, especialmente com o propósito de que as crianças pudessem se envolver com uma atividade artesanal e, coletivamente, pudessem ouvir e contar suas histórias, espontaneamente, enquanto teciam uma colcha.

Nos primeiros encontros eu já havia comentado com as crianças sobre a ideia de fazermos uma colcha de retalhos, a qual poderia depois ser utilizada como um 
tapete para contarem histórias. Como havia o interesse de saber o que a colcha de retalhos representaria e significaria para as crianças, incluindo o fato de elas a confeccionarem, deixei que elas indicassem as sugestões metodológicas, ou seja, que elas propusessem as formas de realizarmos o trabalho e assim pudessem também definir seu sentido. De fato, eu tinha uma proposta provisória, mas não queria que a proposta principal do trabalho fosse por mim sugerida, mas que viesse das crianças. Eis que delas vieram algumas sugestões muito significativas, como por exemplo:

Menina: - Tipo, quem que tem retalho em casa pode pegar um e pensar por que que trouxe aquele retalho, pensando, é, em alguma lembrança que já teve. Daí coloca no tapete e se lembra que aquele retalho é daquela história.

Esse relato é um exemplo que reforça a proposta pensada para a confecção da colcha de retalhos. Enfatizo, ainda, que essa oficina teve várias intenções. Uma delas era de que a composição da colcha fosse a representação das histórias e experiências das crianças. O objetivo era também tornar o momento uma possibilidade de criação de histórias para as crianças, com um encaminhamento teórico-metodológico que tivesse, novamente, uma perspectiva benjaminiana, em que as crianças pudessem se envolver com um trabalho manual, de criação e de encontro.

Para compor a colcha de retalhos nos organizamos em roda sobre o tapete em que costumávamos nos sentar e arrumamos todos os materiais que tínhamos à disposição: um tecido grande que serviu de base estendido ao centro, os retalhos que tanto eu quanto as crianças havíamos trazido. Eu estive junto com as crianças o tempo todo, auxiliando-as e orientando-as, mas procurando intervir o mínimo possível no trabalho. Por outro lado, estive muito atenta às conversas das crianças, especialmente quando percebia que dali surgiria alguma história, para que, se necessário, pudesse fazer alguma pergunta e saber mais sobre a experiência.

Durante todo o tempo em que as crianças estiveram envolvidas com o feitio da colcha de retalhos, suas conversas foram principalmente relacionadas à atividade, isto é, sobre a decisão de que retalho colar, como o recortar, sobre a divisão do espaço no tapete ou até mesmo para decidir que figura do retalho ficaria melhor na colcha, se a corujinha ou a flor. No entanto, junto às conversas, algumas histórias se fizeram, motivadas por algum retalho de tecido que lhes trouxe uma lembrança. 


\section{$O$ retalho da coberta do pai}

Menina: - Esse pedaço aqui é desde que o meu pai era pequeninho, da coberta do pai. Esse paninho foi uma coberta de quando meu pai tinha uns dois aninhos.

Pesquisadora: - Quem contou isso para você?

Menina: - O pai! Na verdade foi minha vó, né, mas o pai contou de novo.

\section{$O$ retalho de pata de cachorro}

Menina: - Olha esse retalho aqui! (com imagem de patas de cachorro).

Agora eu ganhei mais um cachorro. Ele é todo peludinho. Eu ganhei de aniversário do namorado da minha prima e ele deu o nome dele de Neguinho, só porque ele é pretinho. E daí, o tio do Vini trouxe o cachorro de volta com um nome mais engraçado do mundo: Ernesto, nome do cachorro.

\section{CONTRIBUiÇÕES DO TEXTO LITERÁRIO PARA A PRODUÇÃO NARRATIVA} ORAL DAS CRIANÇAS

As crianças produziram histórias a partir das suas experiências, consideradas por elas como as mais significativas, embora com estratégias diferentes. Nesse caso, enfatizo a relação entre o texto literário e as narrativas pessoais produzidas oralmente pelas crianças, em que a literatura infantil se tornou uma referência.

As narrativas apresentadas neste texto se referem ainda à importante decisão que foi para as crianças trazerem para os encontros algo que para elas significasse alguma coisa, como as narrativas que para elas valiam ouro, assim como na oficina "Nossas roupas contam histórias”, em que as crianças trouxeram alguma roupa ou tecido que tinha um significado especial para elas e que continha lembranças de uma experiência vivida.

As narrativas das crianças que tiveram como tema "lembranças” são representações de um discurso do passado, que se constituiu por um exercício de retomada, de rememoração das histórias da própria vida delas, da sua existência. Trata-se de um discurso constituído de fios de memória e, especialmente, de apreciações muito pessoais das crianças, pois muitas histórias foram selecionadas por elas para serem narradas e definidas como lembranças de momentos significativos de suas vidas.

Ao rememorar experiências do passado e selecionar uma lembrança e defini-la como a mais importante, a criança narradora tornou aquela experiência completa - singular (DEWEY, 2010). A experiência das crianças com a narração oral de 
histórias, com a arte da comunicação, em especial com a literatura infantil, possibilitou-lhes intensificarem o presente pelas suas histórias do passado, uma vez que "a arte celebra com intensidade peculiar os momentos em que o passado reforça o presente e em que o futuro é uma intensificação do que existe agora” (DEWEY, 2010, p. 82).

Para Dewey (2010, p. 420-421), a literatura, enquanto arte e comparada às outras artes, exibe um traço singular, pois a literatura expressa seus sons "submetidos a uma arte transformadora"- "arte literatura" -, que tem seu material carregado de "sentidos absorvidos por tempos imemoriais" e com uma "força intelectual superior à de qualquer outra arte". É possível dialogar com a filosofia da arte deweyana e pensar sobre a potencialidade da narração oral de histórias enquanto uma arte que toma como referência diferentes experiências e as expressa por meio da linguagem do narrador, que envolve o gesto, o olhar e a presença corporal, e possibilita criar novas experiências.

Como bem disse Greene (1995, p. 20), a partir de princípios deweyanos, a habilidade de relembrar coisas passadas permite uma reflexão sobre nossas histórias de vida e a retomada de lugares onde já estivemos, e é essa lembrança que torna possível "captar e compreender aquilo que nos acontece hoje ao nosso redor". Além disso, "falar sobre o passado com histórias sobre nós, para nós mesmos e para outros tem um importante papel em nossa vida, pois participa na construção de nosso autoconceito" (MACEDO; SPERB, 2007, p. 236).

Mas um dos aspectos que destaco foi o contato das crianças com o texto literário, a partir do que elas puderam tê-lo como mais uma referência importante para as suas produções orais, reelaborando-o e criando as suas próprias histórias, contadas a partir de suas experiências. Isso indica o "caráter dialógico" do discurso narrativo das crianças, de modo que, "é ouvindo histórias (lidas e também contadas livremente, inspiradas na literatura infantil ou na experiência vivida) e vendo ouvidas as suas próprias histórias que elas aprendem desde muito cedo a tecer narrativamente sua experiência", ao mesmo tempo em que se constituem como "sujeitos culturais" (GIRARDELLO, 2007, p. 54-55).

A partir das obras literárias Guilherme Augusto Araújo Fernandes e Colcha de retalhos, as crianças produziram outras histórias relacionadas às suas vivências pessoais. O texto literário, pelos seus diferentes personagens e enredos, proporcionou às crianças rememorarem suas vivências e nos contarem isso como histórias de vida.

Trata-se de uma relação dialógica e de sentidos com as palavras do outro, ou seja, o contato das crianças com o texto literário. Apoio-me, ainda, nas considerações de 
que "nosso discurso, isto é, todos os nossos enunciados (inclusive as obras criadas), é pleno de palavras dos outros, de um grau vário de alteridade ou de assimilabilidade, de um grau vário de aperceptibilidade e de relevância". Sobretudo, porque as "palavras dos outros trazem consigo a sua expressão, o seu tom valorativo que assimilamos, reelaboramos, e reacentuamos" (BAKHTIN, 2003, p. 294-295). Este foi o exercício que as crianças fizeram - assimilar, reelaborar e reacentuar as palavras do texto literário para criarem as suas histórias.

Há outros exemplos de narrativas orais que também poderiam ser citadas. É o caso em que as crianças se utilizaram de elementos narrativos muito parecidos com os dos contos tradicionais da literatura infantil - uma vez, um dia. As crianças os utilizaram para indicar ao ouvinte uma temporalidade, isto é, para dizer quando a história aconteceu. É um indicativo de que elas se apropriaram de outros textos para constituir suas narrativas, textos que elas podem ter conhecido pela oralidade ou pela escrita. Ao se apropriarem de recursos narrativos de outros textos, as crianças estabelecem sua autonomia de narração, tanto no nível léxico quanto no nível do discurso (PERRONI, 2002). E as crianças, ao narrarem suas histórias, fizeram-no de uma maneira muito espontânea, o que mostra que a linguagem literária já está incorporada em seu discurso e que elas a entendem como uma linguagem para contar histórias.

As histórias das crianças, que tiveram o texto literário como potencializador de suas produções, são representações, também, da estreita relação que há entre narrativa, experiência e imaginação. Além disso, confirmam a possibilidade de que as crianças, enquanto produziram suas narrativas orais, puderam incluir em suas experiências aquelas que foram vividas na imaginação, como, por exemplo, as histórias da literatura infantil.

Sobre a imaginação infantil, Girardello (2011b) aponta a arte e a narrativa como fatores favoráveis para o desenvolvimento da imaginação na infância. Ao examinar aspectos da vida imaginativa infantil, a partir de diferentes autores ${ }^{6}$, Girardello (2011b, p. 82) enfatiza que a narrativa desempenha um papel importante na imaginação da criança, e assinala que as crianças "têm necessidade das imagens fornecidas pelas histórias como estímulo para sua própria criação subjetiva, para sua exploração estética e afetiva”. Para a autora, isso envolve tanto os contos literários como os causos contados em rodas de conversas.

6. Alguns autores que discutem a relação entre imaginação infantil e narrativa que podem ser citados: Jacqueline Held (1980) “O imaginário no poder: as crianças e a literatura fantástica”, e Georges Jean (1990) "Los senderos de la imaginación infantil: los cuentos, los poemas, la realidad”. 
A partir disso, compreendo que a literatura infantil pode contribuir de maneira muito significativa para o desenvolvimento da imaginação infantil pelas possibilidades de experiências que proporciona à criança (apenas como exemplo: experiência estética, de criação, imaginativa e de cultura).

Por outro lado, é importante reconhecer que, "mesmo na linguagem cotidiana dita comum, o sujeito narrativo que fala da sua história submete-se, sabendo ou não, aos mesmos mecanismos que regem as sutis narrações literárias contemporâneas - e dos quais tiram ao mesmo tempo sua vitalidade e sua fragilidade" (GAGNEBIN, 2011, p. 84). Ao mesmo tempo, a literatura confirma a experiência humana e tem seus principais conteúdos presentes na vida (CANDIDO, 2002, p. 81-82).

A relação desses elementos, analisados com os apontamentos de Kearney (2012, p. 417) sobre a narrativa, permitiria ainda falar do poder das histórias: "as histórias nos alteram, ao nos transportar para outros tempos e lugares, onde podemos experimentar as coisas de outro modo". Igualmente, é possível relacionar ao que Kearney chamou de "o poder catártico das histórias", associado à ideia de "liberação" (catharsis). Ou seja, pelas histórias, poder colocar-se no lugar do outro. Um jogo de "diferença e identidade - experimentar a si próprio como outro e o outro como a si próprio - que provoca uma reversão de nossa atitude natural diante das coisas e nos abre novas maneiras de ver e ser" (KEARNEY, 2012, p. 419). Assim, contar histórias nos torna sujeitos à narrativa como também sujeitos da narrativa (KEARNEY, 2012, p. 428).

\section{Algumas considerações}

Alguns resultados da pesquisa apontam que a narrativa não apenas expressa experiências, mas também as cria, e ouvir e narrar histórias se tornou para as crianças, também, um processo de criação. Nesse contexto, um aspecto importante das produções narrativas orais das crianças foi a possibilidade de ter o texto literário como referência para a criação de narrativas pessoais.

As narrativas que se produziram entre experiências vividas e imaginárias evidenciam a proposta pensada para as oficinas: estimular a produção de narrativas orais a partir das experiências vividas pelas crianças. Por outro lado, confirmam a possibilidade de que as crianças, enquanto produziam suas narrativas orais, puderam incluir em suas experiências aquelas que fazem parte do seu repertório cultural, como, por exemplo, as histórias da literatura infantil. 
A criança, ao "inventar uma história", toma parte dos elementos de suas "experiências reais vividas", mas é a combinação desses elementos que constitui sua história em algo novo (JOBIM E SOUZA, 2006, p. 148).

Ficou evidente uma estreita relação entre narrativa e experiência, o que reforça o entendimento de que o sujeito se constitui na e pela palavra. É na e pela palavra, também, que o sujeito pode dar sentido às suas experiências de vida e expressá-las. Eis o que as crianças fizeram, narrativamente.

Por fim, enfatizo, a pesquisa aponta elementos que ajudam a defender a importância de se proporcionar mais tempo na escola para experiências artísticas que incluam a literatura infantil e a narração oral de histórias e que possibilitem às crianças contarem e compartilharem suas histórias junto aos professores, não só pela potencialidade de aprendizagens que isso possibilita, mas, também, por representar práticas educativas associadas a uma pedagogia mais poética e estética.

\section{REFERÊNCIAS}

ABRAMOWICZ, A. A pesquisa com crianças em infâncias e a sociologia da infância. In: FINCO, D. (Org.). Sociologia da infância no Brasil. Campinas/SP: Autores Associados, 2011.

BAKHTIN, Mikhail. Estética da criação verbal. Tradução de Paulo Bezerra. São Paulo: Martins Fontes, 2003.

BENJAMIN, W. Magia e técnica, arte e política. Obras escolhidas. São Paulo: Editora Brasiliense, 1994. BENJAMIN, Walter. Rua de mão única. Obras escolhidas II. Tradução de Rubens Rodrigues Torres Filho e José Carlos Martins Barbosa. São Paulo: Editora Brasiliense, 2011.

CANDIDO, A. A literatura e a formação do homem. In: CANDIDO, A. Textos de intervenção. Seleção, apresentações e notas de Vinicius Dantas. São Paulo: Duas Cidades. Editora 34: 2002.

CLANDININ, D. J.; CONNELLY, F. M. Pesquisa narrativa: experiências e história na pesquisa qualitativa. Tradução: Grupo de Pesquisa Narrativa e Educação de Professores ILEEL/UFU. Uberlândia: EDUFU, 2015.

DELGADO, A. C. C.; MÜLLER, F. Abordagens etnográficas nas pesquisas com crianças e suas culturas. In: REUNIÃO DA ASSOCIAÇÃO NACIONAL DE PESQUISA EM EDUCAÇÃO, 28, Caxambu, 2005. Disponível em: <http://www.28reuniao.anped.org.br/textos/gto7/gto781int. $\mathrm{rtf}>$. Acesso em: 26 mar. 2015.

DEWEY, J. Arte como experiência. Tradução de Vera Ribeiro. São Paulo: Martins Fontes, 2010.

FOX, M. Guilherme Augusto Araújo Fernandes. Tradução de Gilda Aquino. São Paulo: BRINQUEBOOK, 1995.

GAGNEBIN, J. M. História e narração em Walter Benjamin. São Paulo: Perspectiva, 2011. 
GIRARDELLO, G. Voz, presença e imaginação: a narração de histórias e as crianças pequenas. In: FRITZEN, C.; CABRAL, G. (Org.). Infância: imaginação e educação em debate. Campinas, SP: Papirus, 2007.

GIRARDELLO, Gilka. Cultura nos anos iniciais do ensino fundamental: produção narrativa infantil e imaginário midiático. Urban Education PhD Program/City University of New York e Programa de Pós-Graduação em Educação da UFRGS, Porto Alegre, 2011a. 75 p. (Relatório Estágio Pós-Doutoral). GIRARDELLO, G. Imaginação: arte e ciência na infância. Pro-Posições, Campinas/SP, v. 22, n.2, p. 75-92, maio/ago. 2011b.

GREENE, M. Releasing the imagination: essays on education, the arts and social change. San Francisco: Jossey-Bass, 1995.

HELD, J. O imaginário no poder: as crianças e a literatura fantástica. São Paulo: Summus, 1980.

JEAN, G. Los senderos de la imaginación infantil: los cuentos, los poemas, la realidad. Traducción de Juan José Utrilla. México, DF.: Fondo de Cultura Económica, 1990.

JOBIM E SOUZA, Solange. Infância e linguagem: Bakhtin, Vygotsky e Benjamin. 1o. ed. Campinas, São Paulo: Papirus, 2006.

KEARNEY, R. Narrativa. Revista Educação e Realidade, Porto Alegre/RS, v. 37, n. 2, p. 409-438, maio/ago., 2012.

KRAMER, S. Autoria e autorização: questões éticas na pesquisa com crianças. Cadernos de Pesquisa, n. 116, p. 41-59, jul. 2002.

LOW, J.; DURKIN, K. Individual differences and consistency in maternal talk style during joint story encoding and retrospection: associations with children's long-term recall. International Journal of Behavioral Development, 25(1), p. 27-36, 2001.

MACEDO, L.; SPERB, T. M. O desenvolvimento da habilidade da criança para narrar experiências pessoais: uma revisão da literatura. Estudos de Psicologia, Natal/RN, v. 12, n. 3, p. 233-241, dez. 2007.

PEREIRA, R. M. R. Pesquisa com crianças. In: MACEDO, N.; PEREIRA, R. R. Infância em Pesquisa.

Rio de Janeiro: Nau, 2012.

PERRONI, Maria Cecília. Desenvolvimento do discurso narrativo. São Paulo: Martins Fontes, 2002.

PETERSON, C.; MCCABE, A. A social interacionist account of developing decontextualized narrative skill. Developmental Psychology, 30(6), p. 937-948, 2003.

SCHNEUWLY, Bernard; DOLZ, Joaquim. Gêneros orais e escritos na escola. Tradução e organização de Roxane Rojo e Glaís Sales Cordeiro. Campinas, SP: Mercado de Letras, 2004.

SILVA, C. C.; RIBEIRO, N. A colcha de retalhos. São Paulo: Editora do Brasil, 2010.

SOUZA, R. J. Ler e compreender: estratégias de leitura. Campinas, SP: Mercado das Letras, 2010.

\section{SOBRE A AUTORA}

Karin Cozer de Campos é graduada em Pedagogia (Universidade Estadual do Oeste do Paraná), tem Mestrado em Educação (Universidade Federal de Santa Catarina) e Doutorado em Educação (Universidade Federal de Santa Catarina). É professora adjunta/pesquisadora da Universidade Estadual do 
Oeste do Paraná. Tem experiência na área da Educação Infantil, Anos Iniciais do Ensino Fundamental e Formação de Professores, com pesquisa nos seguintes temas: narração oral de histórias, infância, cultura, literatura infantil e formação de professores. Integrante do Grupo de Pesquisa Educação, Criança e Infância (UNIOESTE) e do Núcleo de Infância, Comunicação, Cultura e Arte (UFSC). E-mail: karincozer@gmail.com.

Recebido em 25 de setembro de 2017 e aprovado em o8 de abril de 2019. 